\title{
Science of adaptation to climate change and science for adaptation
}

\author{
Rob Swart ${ }^{1 *}$, Robbert Biesbroek ${ }^{2}$ and Tiago Capela Lourenço ${ }^{3}$ \\ ${ }^{1}$ Climate Change and Adaptive Land and Water Management Team, Alterra, Wageningen University and Research Centre, Wageningen, Netherlands \\ 2 Public Administration and Policy Group, Wageningen University and Research Centre, Wageningen, Netherlands \\ ${ }^{3}$ Foundation Faculty of Sciences, University of Lisbon, Lisbon, Portugal
}

\section{Edited by:}

Veerasamy Sejian, Indian Council of Agricultural Research, India

\section{Reviewed by:}

Julia Hidalgo, Laboratoire

Interdisciplinaire, Solidarités,

Sociétés, Territoires, France

Carlo Giupponi, Università Ca'

Foscari di Venezia, Italy

*Correspondence:

Rob Swart, Climate Change and

Adaptive Land and Water

Management Team, Alterra,

Wageningen University and

Research Centre,

Droevendaalsesteeg 3a, Building

100, 6708 PB Wageningen,

Netherlands

e-mail: rob.swart@wur.n
Adaptation to climate change has gained a prominent place next to mitigation on global, national, and local policy agendas. However, while an abundance of adaptation strategies, plans, and programmes have been developed, progress in turning these into action has been slow. The development of a sound knowledge basis to support adaptation globally is suggested to accelerate progress, but has lagged behind. The emphasis in both current and newly proposed programmes is very much on practice-oriented research with strong stakeholder participation. This paper supports such practice-oriented research, but argues that this is insufficient to support adaptation policy and practice in a productive manner. We argue that there is not only a need for science for adaptation, but also a science of adaptation. The paper argues that participatory, practice-oriented research is indeed essential, but has to be complemented by and connected to more fundamental inquiry and concept development, which takes into account knowledge that has been developed in disciplinary sciences and on issues other than climate change adaptation. At the same time, the level and method of participation in science for adaptation should be determined on the basis of the specific project context and goals. More emphasis on science of adaptation can lead to improved understanding of the conditions for successful science for adaptation.

Keywords: climate change adaptation, science of adaptation, science for adaptation, transdisciplinarity, adaptation research

\section{INTRODUCTION}

Ever since the perceived taboo on adaptation to climate change has been lifted (Pielke et al., 2007), adaptation has become politically accepted and institutionalized at different levels of governance: for example, through the establishment of financial instruments at the global level of the United National Framework Convention on Climate Change (UNFCCC), the European Union's Climate Change Adaptation Strategy, the increasing number of National Climate Change Adaptation Strategies and plans, and the numerous local and regional initiatives to plan for future climate change risks (Biesbroek et al., 2010; Dreyfus and Patt, 2012). Many examples of adaptation have been reported and now serve as an inspiration for future adaptation efforts across the globe. Still, the World Economic Forum considers the failure to adapt to climate change to be one of the major threats that society faces in the coming decades (WEF, 2013, 2014), requiring even more adaptation action.

In parallel to the policy progress, scientific endeavors on understanding different dimensions of adaptation to climate change and the number of scholarly papers has increased substantially in recent years (Berrang-Ford et al., 2011). The recently published 5th Assessment report of IPCC Working Group II is the most recent assessment of the scientific progress on adaptation. Where previous research has explored the impacts and vulnerabilities of climate risks, recent emphasis in adaptation research programmes, globally, and in Europe, has been on responses, in particular on the softer kind of measures such as capacity building, management, and planning, awareness raising and supply of information, but less on actually changing practices, green or gray infrastructure, or measurable decrease of vulnerability (EEA, 2013; Biagini et al., 2014). Moss et al. (2013) argue that inadequate knowledge for adaptation forms one important reason why progress in delivering adaptation action has been limited. Research to support adaptation therefore needs to move toward other forms of research that better connects to the societal needs (Moser, 2010; O'Brien, 2012; Deppisch and Hasibovic, 2013). Conventional disciplinary approaches are considered to be insufficiently equipped to deal with the intricately connected and inherently wicked nature of climate change risks in a holistic way (ISSC/UNESCO, 2013). A multidisciplinary or interdisciplinary approach, where disciplinary knowledge is, respectively, exchanged or integrated, is deemed necessary but not sufficient to tackle these societally relevant problems either.

The inability to connect the sciences meaningfully with societal needs has been central to different academic disciplines and philosophy of science (Nowotny et al., 2001) and recently entered the discussion on climate change adaptation (see amongst others Moser and Boykoff, 2013) and its connections with climate risk 
management approaches (IPCC, 2012), namely those that aim at combining adaptation and disaster risk reduction processes. It is argued that future research on climate change adaptation would require the involvement of non-scientific stakeholders in the research enterprise so as to co-define societally relevant problems, to co-produce or co-create relevant knowledge, and to co-learn from these experiences, which in this paper, we consider to be captured by the term "transdisciplinary" (Mauser et al., 2013; Rice, 2013). The term "transdisciplinary" is defined differently in different contexts and its meaning has evolved over time. Defining characteristics are usually problem focus, evolving methodology, and collaboration, with a different balance in different contexts (Wickson et al., 2006; Russell et al., 2008). Nowotny et al. (2001) refer to "knowledge production that is problem-oriented, responsive and open to external knowledge producers, contextualized, and systems-based, adaptable, consultative and socially robust." As we observe in the next section, the involvement of external knowledge producers is typical for the definition used in climate change adaptation programming. So, in this paper we explicitly refer to kinds of transdisciplinary research that does create knowledge beyond disciplinary borders and does also involve stakeholders. The ontological questions of what constitutes a transdisciplinary approach, how it originated, and how its success can be evaluated is beyond the scope of this article (Pohl, 2008, 2011). Yet one defining characteristic, namely problem orientation through a participatory approach is central to this paper. It has been argued that transdisciplinary research is particularly relevant when knowledge is uncertain, the nature of the problem disputed and the consequences of the problem affect large parts of society (Hirsch Hadorn et al., 2007). Although the precise onset of this movement in the recent past remains difficult to identify in time, we observe that the scientific discourse on adaptation seems to move in the direction of one unified, practice-oriented, transdisciplinary form of science aiming to inform "decision makers," even though it is often unclear who exactly these decision makers are or which precise questions they have. This movement can be regarded as part of a broader trend which Bäckstrand et al. (2010) labeled the deliberative turn in environmental governance. Although there can be no objection against socially relevant research on adaptation, we feel that there are some critical reflections and nuances currently missing in the debates on the future of adaptation research, which we will discuss in this paper.

First, we review some of the key elements of current and proposed adaptation research programmes related to practiceoriented research and identify their strengths and weaknesseswhich we call the science for adaptation. Then we focus on the need for-and early efforts on-a science of adaptation. Finally, we discuss a number of future directions that this research can take to build both a science for and of adaptation, and connections between them.

\section{PRACTICE-ORIENTED RESEARCH PROGRAMMES ON CLIMATE CHANGE ADAPTATION}

Although the call for transdisciplinary and practice-oriented research on adaptation has been relatively recent, several research programmes aiming to support adaptation that reflect this call have already been developed and, in some countries, implemented (Mauser et al., 2013). Some important programmes are summarized below. We illustrate this trend by highlighting the ambitions of several exemplary transdisciplinary research and funding programs at international, European and national levels. As these research programmes are often still in the implementation or proposal stage, a systematic quantitative analysis of published papers on climate change adaptation projects funded through these programmes is not yet possible.

At the global level, the Future Earth programme is perhaps most relevant for adaptation research. Although the programme targets sustainability issues wider than adaptation, it provides a global umbrella for adaptation-relevant research (Future Earth, 2013). To address the challenge that science has up-to-now tended to provide mainly understanding but not answers or comprehensive solutions to sustainability questions, Future Earth proposes co-design and co-production of research, noting that this kind of research is also sometimes referred to as "transdisciplinary" (Future Earth, 2013).

A major new research initiative in Europe in support of climate change adaptation policy development is the Joint Programming Initiative (JPI) Climate a collaboration between 14 European countries to coordinate jointly their climate research and fund new transnational research initiatives. JPI Climate intends to connect scientific disciplines, enable cross-border research, and increase science-practice interactions (JPI Climate, 2010). One of the four elements of JPI Climate specifically aims at "facilitating transdisciplinary exchange on the objectives, the framework conditions and the realization of sustainable societal transformations toward "carbon neutral," adaptive and climate-proof European societies through interaction and joint initiatives with stakeholders as knowledge partners.” Another JPI element focuses on improving models and scenario-based tools for decision-making under climate change, tools which "will be further developed, compared, and applied in close interaction and dialogue between researchers and stakeholders at different levels."

JPI Climate could be regarded as the EU Member State counterpart of the new Horizon2020 (H2020) programme. This latter programme is a new major endeavor of the European Commission with three main objectives: excellent science, industrial leadership, and societal challenges. The total budget is nearly $€ 80$ billion, of which more than $€ 15$ billion over the first 2 years, 35\% of which should be climate related (EC, 2013). Although H2020 is more oriented toward policy support than its Framework Programme predecessors, transdisciplinarity is not explicitly identified as an action point. Nonetheless, the programme extensively calls for user-driven (or -relevant) research and societal engagement, explicitly embedding Social Sciences and Humanities ( $\mathrm{SSH}$ ), which is also meant to stimulate interdisciplinarity and, to a certain extent, transdisciplinarity (integrating also non-disciplinary knowledge). Transdisciplinarity is furthermore fostered via the actions under EU's Responsible Research and Innovation (RRI) activities (Pauli, 2013). Projects combining research and innovation, aiming at developing markets in collaboration with private sector partners, in particular SMEs, are at the core of $\mathrm{H} 2020$. 
Pertinent examples of targeted climate change adaptation research programmes at the national level are the KLIMZUG programme in Germany (Bardt et al., 2012) and the Knowledge for Climate Programme in The Netherlands (Hegger et al., 2012; Knowledge for Climate, 2012). Both programmes built on predecessors that focused more on assessment of impacts and vulnerability (klimazwei, and Climate changes Spatial Planning, respectively). Other programmes of groups of projects that have a participatory component have been developed in countries like Japan (Tamura et al., 2014), Australia (NCCARF, 2012), the United States (Moss et al., 2014), Finland, and the United Kingdom. Also the Austrian Climate Research Programme encourages interdisciplinary and transdisciplinary project proposals, "to enhance the quality of project applications and international visibility and knowledge transfer to Austria" (ACRP, 2014).

These examples confirm that current and proposed research programmes relevant for adaptation to climate change at all levels tend to focus mainly, or sometimes exclusively, on practiceoriented research in support of adaptation decision-making. They draw from existing fundamental disciplinary knowledge, but pay less attention to more fundamental research leading to appropriate theoretical frameworks and associated methodologies for adaptation to climate change. Below we discuss the pros and cons of this approach.

\section{SCIENCE FOR ADAPTATION: PRACTICE-ORIENTED RESEARCH AND BRIDGING THE SCIENCE-POLICY-PRACTICE DIVIDE}

The research programmes above demonstrate considerable efforts in practice-oriented research on adaptation. However, one could pose the question if it would be justified to develop a distinct, novel "adaptation science" to support adaptation, or if adaptation is mainly an act of practice, one that can be studied using multiple scientific perspectives. This question is yet to be answered. Some have argued that there are at least some signs of such an emerging "adaptation science." According to Moss et al. (2013), adaptation science is at best still in a formative stage. To address the question what it is and how it may develop, we make the analytical distinction between science on adaptation and science for adaptation, see Figure 1.

Moss et al. (2013) provide a comprehensive proposal for the development of an integrated and practice-relevant adaptation science, to understand decision processes and knowledge requirements, identify vulnerabilities, improve foresight about climate risks and other stressors, and understand barriers and options for adaptation (Moss et al., 2013). Practice-oriented or socially relevant research is unquestionably of utmost importance, and is justified for many societal challenges, including adaptation. However, to what extent does transdisciplinary research indeed lead to societal impacts, e.g., in terms of decreased vulnerability to climate change? More co-produced knowledge is often assumed to lead to more and better adaptation because of tangible connections between the research and social needs and interests (Hegger et al., 2012). But is this really true? An evaluation of the societal impact of the two Dutch climate change research programmes suggests that the impact has been greatest on agenda setting

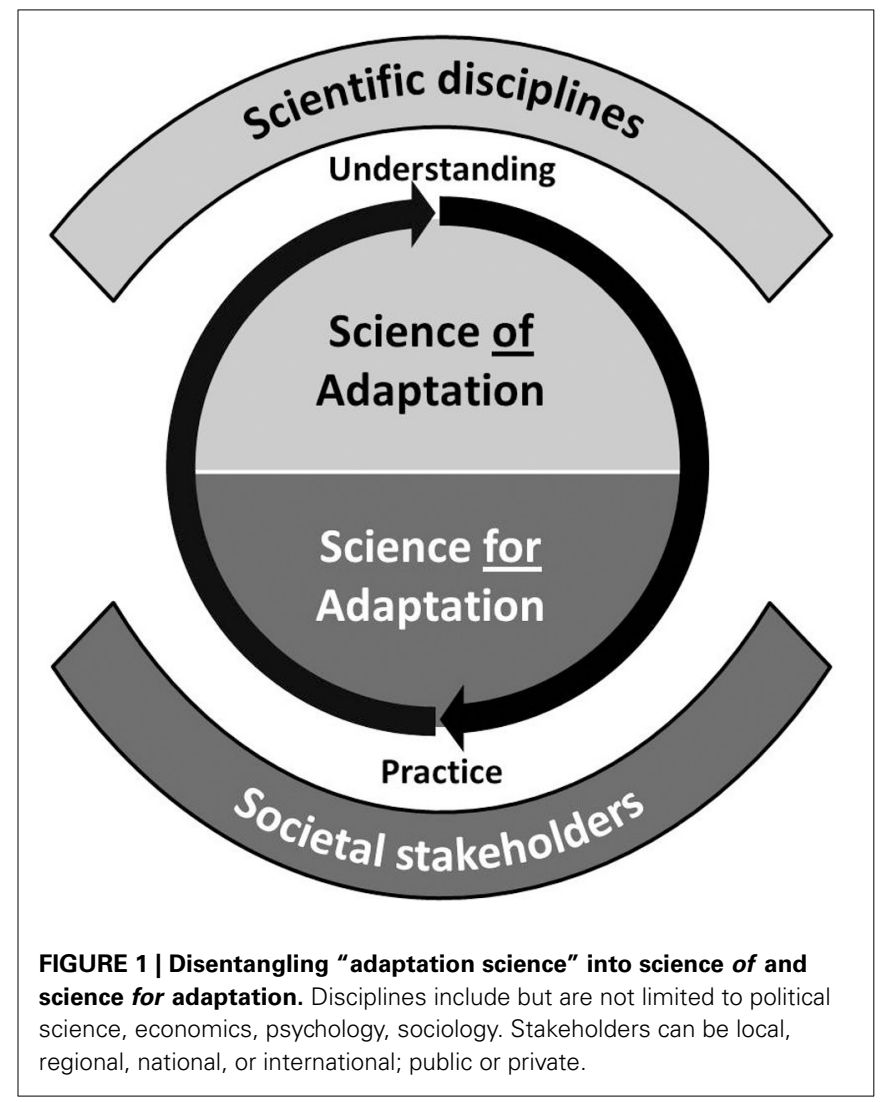

(Merkx et al., 2012). Knowledge on climate change amongst societal actors has been increased, the magnitude, and diversity of networks have been improved, tools have been developed that are also used by actors not involved in the programme, and knowledge has effectively been co-created. However, with a few exceptions, these positive outcomes have generally not led to actual implementation of adaptation actions, and the durability of the impacts is uncertain (Merkx et al., 2012).

We identify several pitfalls of too much emphasis on an imprecisely defined, transdisciplinary, practice-oriented form of research - a science for adaptation without a substantive science of adaptation. While these pitfalls can be expected to reduce the quality and social impact of this kind of research, this does not imply that addressing these pitfalls will automatically lead to action, since other factors play a role as well, including the limitations of scientific knowledge in general as a driver for societal action (Biesbroek et al., 2013a). We start from the premise that by taking away these barriers the chance of success may be enhanced, and more emphasis on a science of adaptation can provide better and more informed interventions in practice. Below we discuss five: (1) application of untested heuristics in practice; (2) scientists as problem-solvers; (3) consensus framing and confusing terminology; (4) unattractiveness for disciplinary researchers, and (5) a one-size-fits-all approach.

(1) Validated and tested theoretical frameworks and hypotheses as well as appropriate and commonly accepted methodologies and data are as yet largely missing. In such a situation, 
practice-oriented adaptation research appears to be driven by unproven assumptions about the effectiveness, costs, and benefits of particular adaptation measures, rather than by a comprehensive, sound analysis of the options, and the conditions under which they may be applied. Preston et al. (2013) argue that current adaptation discussions rely on heuristics that are scientifically untested but which nevertheless resurface in most practices. Such heuristic devices shape how we see adaptation and they influence the policy decisions-practices thrive on heuristic reasoning. The use of largely untested heuristic devices, such as "better adaptation outcomes require stakeholder involvement" (Burton and Mustelin, 2013) or "adaptation is novel and there are no experiences to draw from" (Bassett and Fogelman, 2013) may sometimes prove to be barriers rather than providing support in search for optimal solutions. In addition, it remains unclear when exactly this call for adaptation transdisciplinarity emerged, raising the question whether it was "imported" from other science-practice arenas or emerged from an evolving community of adaptation researchers.

(2) A second pitfall is the challenge of unconscious convergence of perspectives between scientists and practitioners which reduces the ability to reflect and innovate. Policy makers are problem solvers by definition; it is their task, their raison d'etre, to help solve societal problems such as climate change adaptation by making policies, programmes, and plans, to provide guidance and support society where needed (Biesbroek et al., 2013b). Policy makers have certain problem framings that do not necessarily match those of scientists. Of course, there are different types of scientists in the climate change adaptation debate, but even for honest knowledge brokers and the most skilled boundary workers, there is the risk that the encouraged closeness between science and practice, forces scientists-inadvertently or involuntarilyto adopt the same paradigmatic lens of the policy maker to connect to a policy framing so as to determine what is socially relevant and practically applicable. Adopting the same problem-solving lens by both science and practice runs the danger that they become trapped in the vicious cycle where the problem-solving paradigm is dominating every discussion and decision on real world problems. Indeed, we know that there are different analytical paradigms, rooted in different traditions, from which to study adaptation ( $O^{\prime} B$ Bien and Hochachka, 2010; Biesbroek et al., 2013b). Fixation on one paradigm, in this case that of the "problem solver," means that those involved are unable to take a step back, reflect, and use other lenses and theories to provide meaningful advice in search of practice-relevant adaptation actions (Carolan, 2004; Biesbroek, 2014). Such reflexive distance is, however, of vital importance (Voss et al., 2006).

(3) Transdisciplinary research may lead to consensus frames that are depoliticized and lack the necessary substance to allow for concrete adaptation action. Experiences from interdisciplinary research show that there are communicative and conceptual barriers brought on by disparate research backgrounds and streams of thought, and that barriers become even more challenging by involving non-academic stakeholders with different motives, ideas, or goals. One of the resulting consequences is the construction of framings of apparent consensus; in other words, searching for common framings and understandings, for example by inventing new words to which people from different backgrounds can relate (see Box 1). Consensus frames are partly the result of the translatability of the disciplinary understandings and the emerging of new scientific discourses. But the rationale for building consensus frames is often in apparent dissensus about values and objectives (Candel et al., 2014) — and introducing new wordings might only be window dressing without resolving the underlying conflicts. Moreover, broadly shared themes such as "adaptation" and "resilience" are rather technical and depoliticized concepts, designed to provide openings for interventions in governance processes. Value-laden issues such as structural inequalities and power asymmetries, which are integral parts of the political nature of adaptation, are then pushed to the background in these governance processes (Vink et al., 2013; Hjerpe et al., 2014). Consequently, while knowledge exchange and shared understandings is often the result of transdisciplinary research, it seldom leads to empowerment and actual implementation (Brandt et al., 2013). These so-called consensus frames may lead to abstract agreements but are of limited value in actual implementation.

(4) Fourth, the current emphasis on practice-oriented, transdisciplinary science for adaptation is rather closed, not very reflexive, nor attractive for disciplinary sciences to be involved in. Dovers and Hezri (2010) for example argue that there is a self-referencing (inter- or transdisciplinary) community, creating its own scientific legitimacy. This could be considered as strength, evidencing an "adaptation science" or as weakness, suggesting closedness and the danger of "reinventing the wheel." Yet the disciplinary sciences are vital since they can bring novel theoretical and methodological insights into the climate change adaptation debate. Of course, involving the disciplinary sciences more strongly has been proclaimed by many others and while some early noteworthy successes can be mentioned (e.g., Rayner and Malone, 1998), disciplinary scientists are still reluctant to be involved because of the transdisciplinary ambitions. For example, political scientist Javeline (2014) points out that many of the pressing questions about adaptation are less about science and more about political, social, and economic behaviors and institutions and that, despite being uniquely trained to address questions in these areas, political scientists have thus far contributed hardly anything to the adaptation research agenda. In addition, from a practical point of view, scientific research on adaptation has become dependent on practice not only to be socially relevant as required by funding agencies, but also increasingly through co-funding of private or local governmental actors seeking information that supports their growing concerns about climate change risks.

(5) A final pitfall of transdisciplinary research is the tendency to assume that the programme objectives can be achieved by a one-size-fits-all approach in which stakeholder involvement is central (heuristic: "involve all relevant stakeholders 


\section{Box 1 | Transdisciplinarity and co-production: more than just new magic concepts?}

In the development of research programmes and projects on adaptation terms such as "resilience," "transdisciplinarity," and "co-design" and "co-production of knowledge" are frequently used. While these terms may play a useful role in forging agreement about strategic directions of these programmes, one may question their usefulness when it comes to implementing specific projects for a specific context. The terms share characteristics with so-called "magic concepts" (Pollitt and Hupe, 2011): broadness (covering large domains and having multiple, overlapping, sometimes conflicting definitions), normative attractiveness (having a positive connotation), implication of consensus (diluting, obscuring, or even denying traditional social science concerns with conflicting interests and logics), and global marketability (being well-known and fashionable). Magic concepts can help to set agendas, to provide a vocabulary for debate, and to attract contracts and grants. At the same time, they are neither very precise nor necessarily stable, and do not provide guidance on followup action (Pollitt and Hupe, 2011). For developing meaningful practice-oriented projects, more precise descriptions of the problems at hand and the methodologies that can be used to address them are required. For this to evolve, we need better science on adaptation.

throughout the process"). In practice, even if there is initial agreement on joint objectives and collaboration, many stakeholders who may be important in theory may delegate the work to staff who appear in the end not to be motivated to become sufficiently involved because of multiple reasons such as lack of time, different perception of project objectives, low expectations about the benefit of participation or simply because they participated in similar activities before and have grown weary of contributing again ("stakeholder fatigue," e.g., see Hedger et al., 2006). Some governance arrangements are designed as open dialogues with stakeholder learning spaces, but do not include the relevant actors with political powers to make decisions. Many transdisciplinary project proposals include plans to engage stakeholders that in practice can fall short of success, because the timing and objectives of the engagement are science rather than policy driven. With lack of evaluation of success of projects afterwards, there is a risk that stakeholder involvement is rhetoric rather than productive in practice (Groot et al., 2014). Working with stakeholders brings the additional challenges of reconciling different time horizons (very short for businesses and policy cycles and long for science) and, in the case of private actors, issues related to the public access of project results. A careful co-design of the project's objectives, timeline, procedures, responsibilities, and outputs tailored to the specific decisionmaking context would clarify the different actor roles from the start, but is often lacking.

\section{SCIENCE OF ADAPTATION: SEARCH FOR DISCIPLINARY PLURALISM}

As discussed above, the science for adaptation evolves mainly in a transdisciplinary fashion, by analyzing how to address societal adaptation challenges in various real-word contexts using available theories and data to describe and advise policy practice. We postulate that good policy recommendations require linkages between science, policy, and society, but it also requires reflexive distance and scientific evidence to support the advice on how to best adapt to climate change. There are obviously potentially intractable conflicts between the aims of the science of adaptation (to better understand) and the science for adaptation (to support policy and practice), but too much focus on the science for adaptation would be problematic since in the end it should be to a large extent dependent on the science of adaptation. The questions posed in the latter might not be immediately socially relevant, but they are necessary to inform meaningful science for adaptation. A science of adaptation would approach adaptation to climate change as an observable societal act that can be studied from different angles and adopting different disciplinary perspectives, grounded in and requiring expertise from the forefront of both natural and social disciplinary sciences, to really understand some of the fundamental aspects of the adaptation. As illustrated in Figure 1, in the context of this paper we specifically imply social science disciplines which have been underrepresented in adaptation research to date. One example is the (a priori) need to embark in stakeholder engagement or co-creation processes as a fundamental step in moving adaptation practice. A science of adaptation can point out if there are recurring patterns and processes in stakeholder involvement across cases that can determine under which conditions certain types of stakeholder involvement is proven to be most effective to implement measures to adapt, or suggest conditions where no or limited participation is perhaps more effective (see for example Few et al., 2007).

In the context of this paper, we define the science of adaptation as a combination of disciplinary research theories and methods, grounded in the classical science traditions, to theorize and test the fundamental assumptions, processes, and principles of adaptation to a changing climate so as to provide an evidence base for the science for adaptation. Such endeavor therefore goes beyond merely including (multi)disciplinary sciences in supporting decision making on adaptation. We propose three potential roles for such science of adaptation: (1) break through heuristics and clarify key concepts; (2) move toward testing and explanatory ambitions; (3) allow for multiplicity of ontological perspectives and methodological variety.

(1) A science of adaptation would aim to understand the more fundamental scientific questions. Despite 15 years of research we are still unable to conceptually disentangle adaptation to climate change from adaptation to environmental change (Dupuis and Biesbroek, 2013). We hardly know what "successful" adaptation means (Doria et al., 2009), or the conditions necessary or sufficient for evaluating successful adaptation. In addition, although definitions of maladaptation have been provided by different authors (e.g., Swart et al., 2014), it has not been systematically analyzed what it implies in theory and practice, and how it might be avoided in different contexts (Barnett and O'Neill, 2010). Other fundamental questions seem to be ignored altogether: 
is adaptation so different from other types of directional change (Chapin et al., 2006)? If so, can we articulate precisely what makes adaptation to climate change so different? If the answer is no, then why are we so vigorously trying to make it into a separate field of research? What does this mean for involving the disciplinary social sciences more actively? Addressing or highlighting these conceptual challenges requires involving the disciplinary sciences more constructively.

(2) A science of adaptation would induce a move from deductive and explorative ambitions toward inductive and confirmatory research designs. Most of the research on adaptation today focussed on small-n case studies, examining a small number of cases in depth to explore why adaptation in that particular case is successful (or not) and, sometimes, which lessons may be applied in other contexts (Ford et al., 2010). Although this type of research has provided valuable insights and some inspirational examples, the context-dependent nature of adaptation makes it difficult to distil, compare, and evaluate insights from such types of studies. Surely, single$\mathrm{n}$ or small-n cases are instructive if proper conditions are met (Flyvbjerg, 2006), but some of the more fundamental questions require other types of research design which are well-known and applied in other areas but not in climate change adaptation. For example, what are the conditions that are necessary or sufficient in explaining why adaptation is or is not successful? When is stakeholder participation in answering this question appropriate and when is it not? Addressing these questions requires new research methods and techniques that have hardly been used in the scholarly community on adaptation today. In addition, some have argued that the move toward explanatory designs is challenging because data sets do not exist, or because of conceptual challenges (Dupuis and Biesbroek, 2013). To move forward in the science of adaptation requires methodological variety and conceptual clarity before comprehensive datasets can be built (Murtinho and Hayes, 2012). Such datasets would allow more active involvement of other sciences. One example for a prospective adaptation research agenda in political science is provided by Javeline (2014): although it is acknowledged by the adaptation research community that adaptation is a political endeavor (Vink et al., 2013), research areas within the political sciences such as comparative politics, public opinion, political partisanship's influence, national security, and others are hardly addressed (for reasons discussed earlier).

(3) A science of adaptation would also more actively engage in debates about the epistemological and ontological underpinnings of the discussion on adaptation, which are currently scarce at best (O'Brien and Hochachka, 2010; Hegger et al., 2012). The value of ontological debates is to better understand the truth-value of existence claims and better understand the multiple ways of knowing. It centers around questions about how to deal with normative ambiguity that is inherent to adaptation practices. How do we perceive the link between climate risk and vulnerability (Dupuis and Knoepfel, 2013)? Transdisciplinary studies include by definition pragmatists who search for, and eclectically combine, existing ideas and theories without considering potential ontological conflicts. By allowing for a science of adaptation, more explicit room for purists' ideas would be opened, and accounting for different ontological perspectives would broaden the scope of what adaptation could look like in practice and how it can be advanced.

\section{CONNECTING SCIENCE OF AND SCIENCE FOR ADAPTATION: A DIVERSIFIED APPROACH}

In this paper, we noted the tendency in current and programmed research on climate change adaptation to move toward a single, transdisciplinary approach with a strong co-production and stakeholder involvement component. We call this the science for adaptation. Patt (2013) raised the question: "what if adaptation isn't really a very good science of its own"? We argue that, alone, the current science for adaptation may not really meet the standard of "a very good science of its own." Furthermore, and considering the importance of adaptation as one of the most pressing societal issues (WEF, 2013, 2014), we do believe it can also be scientifically strengthened. We therefore plea for a scientific endeavor that captures and balances both science for and of adaptation. Whether this combination should be called "adaptation science" may not be a very meaningful question from a purely scientific perspective. It may be of practical and linguistic interest, for example when developing specific (new) journals, in the design of academic courses and research programmes, financing disciplinary research projects of adaptation, or even the development of new academic or other institutions.

Rather than suggesting to develop a "science of adaptation" research line in parallel to the current science for adaptation, we here more modestly suggest to correct the growing bias in the current adaptation research programmes and funding schemes toward a better balance between science for and of adaptation. This would recognize that some distance between these two types of research is needed for reflection, synthesis, and further learning. While we acknowledge that learning by doing in participatory, practice-oriented research is useful and can be productive, we also argue that a better understanding of the underlying theoretical frames and processes can lead to a more effective support to decision-making processes on the longer-term; it is too soon to only focus on transdisciplinary and practice-oriented research. Here, we refer to social science questions about what exactly does adaptation entail, both theoretically and conceptually, enhancing an understanding that may be as-or even more- important than improvements in climate modeling or impact studies for advancing climate change adaptation in practice.

Strengthening the science for adaptation requires overcoming a number of barriers created by the move toward transdisciplinary research and how the research on adaptation has evolved: (1) application of untested heuristics in practice; (2) scientists as problem-solvers; (3) confusion about framing and terminology; (4) unattractiveness for disciplinary researchers, and (5) one-size-fits-all approaches. In particular, we feel that the idea of the transdisciplinary research endeavor will not be sufficiently attractive to involve the disciplinary social sciences. A better understanding is required of the types of knowledge that are 
needed to support the science for adaptation which, in turn, allow to allocate scientific research funding to disciplinary focussed research projects that may not be of immediate societal relevance. In particular, we propose to give more weight in climate change adaptation research to science of adaptation that would encourage to (1) break through heuristics and clarify key concepts; (2) move toward testing and explanatory ambitions, and (3) allow for multiplicity of ontological perspectives and methodological variety.

A new generation of scholars on climate change adaptation might be able to connect across scientific disciplines, be sensitive to practice-relevant questions, to couple science and practice, and to provide clear and simple stories (Mustelin et al., 2013). They are an integral component for the success of the practiceoriented research endeavor. We envision an important share of the new generation of scholars on climate change adaptation to be generalists, educated to assist addressing real world problems. But this means that there is also an increasing need for a science of adaptation-to provide substantive insights and recommendations to support transdisciplinary research. This combination of disciplinary, interdisciplinary, and transdisciplinary research would encourage a broader spectrum of relevant disciplinary sciences to become involved in adaptation science beyond just a transdisciplinary, practice-oriented approach.

If research funding and programming agencies would aim to strike a good balance between a science for adaptation and a science of adaptation, the societal impacts can be much larger than a sole focus on practice-oriented science, which may lead to a million case studies without necessarily a good understanding of underlying processes or the development of appropriate frameworks and methodologies. We hope that in the new Interdisciplinary Climate Studies journal of Frontiers in Environmental Science there will be room for both a science for adaptation and a science of adaptation.

\section{REFERENCES}

ACRP. (2014). 7th Call for Proposals-Guide for The Submission of Proposals. Vienna: Austrian Climate Research Programme.

Bäckstrand, K., Khan, J., Kronsell, A., and Lövbrand, E. (2010). Environmental Politics and Deliberative Democracy —Examining the Promise of New Modes of Governance. Cheltenham: Edward Elgar. doi: 10.4337/9781849806411

Bardt, H., Biebeler, H., Chrischilles, E., and Mahammadzadeh, M. (2012). Klimzug: Climate Change in Regions. Adaptation Strategies for Seven Regions. Cologne: Cologne Institute for Economic Research.

Barnett, J., and O'Neill, S. (2010). Maladaptation. Glob. Environ. Change 20, 211-213. doi: 10.1016/j.gloenvcha.2009.11.004

Bassett, T. J., and Fogelman, C. (2013). Déjà vu or something new? The adaptation concept in the climate change literature. Geoforum 48, 42-53. doi: 10.1016/j.geoforum.2013.04.010

Berrang-Ford, L., Ford, J. D., and Paterson, J. (2011). Are we adapting to climate change? Glob. Environ. Change 21, 25-33. doi: 10.1016/j.gloenvcha.2010.09.012

Biagini, B., Biermaum, R., Stults, M., Dobardzic, S., and McNeeley, S. M. (2014). A typology of adaptation actions: a global look at climate adaptation actions financed through the Global Environment Facility. Glob. Environ. Change. 25, 97-108. doi: 10.1016/j.gloenvcha.2014.01.003

Biesbroek, G. R. (2014). Challenging Barriers in The Governance of Climate Change Adaptation. Ph.D. thesis, Wageningen: Wageningen University.

Biesbroek, G. R., Swart, R. J., Carter, T. R., Cowan, C., Henrichs, T., Mela, H., et al. (2010). Europe adapts to climate change: comparing national adaptation strategies. Glob. Environ. Change 20, 440-450. doi: 10.1016/j.gloenvcha.2010. 03.005
Biesbroek, G. R., Termeer, C. J. A. M., Klostermann, J. E. M., and Kabat, P. (2013a). On the nature of barriers to climate change adaptation. Reg. Environ. Change 13, 1119-1129. doi: 10.1007/s10113-013-0421-y

Biesbroek, G. R., Termeer, C. J. A. M., Klostermann, J. E. M., and Kabat, P. (2013b) Analytical lenses on barriers in the governance of climate change adaptation. Mitig. Adapt. Strat. Glob. Change 1-20. doi: 10.1007/s11027-013-9457-z

Brandt, P. A., Ernst, F., Gralla, C., Luederitz, D. J., Lang, J., Newig, F., et al. (2013). A review of transdisciplinary research in sustainability science. Ecol. Econ. 92, 1-15. doi: 10.1016/j.ecolecon.2013.04.008

Burton, P., and Mustelin, J. (2013). Planning for climate change: is greater public participation the key to success? Urban Policy Res. 31, 399-415. doi: 10.1080/08111146.2013.778196

Candel, J. J. L., Breeman, G. E., Stiller, S. J., and Termeer, C. J. A. M. (2014). Disentangling the consensus frame of food security: the case of the EU Common Agricultural Policy reform debate. Food Policy 44, 47-58. doi: 10.1016/j.foodpol.2013.10.005

Carolan, M. S. (2004). Ontological politics: mapping a complex environmental problem. Environ. Values 13, 497-522. doi: 10.3197/0963271042772587

Chapin, F. S., Lovecraft, A. L., Zavaleta, E. S., Nelson, J., Robards, M. D., Kofinas, G. P., et al. (2006). Policy strategies to address sustainability of Alaskan boreal forests in response to a directionally changing climate. Proc. Natl. Acad. Sci. U.S.A. 103, 16637-16643. doi: 10.1073/pnas.0606955103

Deppisch, S., and Hasibovic, S. (2013). Social-ecological resilience thinking as a bridging concept in transdisciplinary research on climate-change adaptation. Nat. Hazards 67, 117-127. doi: 10.1007/s11069-011-9821-9

Doria, M. D. F., Boyd, E., Tompkins, E. L., and Adger, W. N. (2009). Using expert elicitation to define successful adaptation to climate change. Environ. Sci. Policy 12, 810-819. doi: 10.1016/j.envsci.2009.04.001

Dovers, S. R., and Hezri, A. A. (2010). Institutions and policy processes: the means to the ends of adaptation. Wiley Interdiscip. Rev. Clim. Change 1, 212-231. doi: $10.1002 /$ wcc. 29

Dreyfus, M., and Patt, A. (2012). The European Commission White Paper on adaptation: appraising its strategic success as an instrument of soft law. Mitig. Adapt. Strat. Glob. Change 17, 849-863. doi: 10.1007/s11027-011-9348-0

Dupuis, J., and Biesbroek, R. (2013). Comparing apples and oranges: the dependent variable problem in comparing and evaluating climate change adaptation policies. Glob. Environ. 23, 1476-1487. doi: 10.1016/j.gloenvcha.2013.07.022

Dupuis, J., and Knoepfel, P. (2013). The adaptation policy paradox: the implementation deficit of policies framed as climate change adaptation. Ecol. Soc. 18:31 doi: 10.5751/ES-05965-180431

EC. (2013). HORIZON 2020 Work Progranmme 2014-2015. European Commission Decision C (2013)8631 of 10 December 2013. Brussels: European Commission.

EEA. (2013). Adaptation in Europe-Addressing Risks and Opportunities From Climate Change in The Context of Socio-Economic Developments. Copenhagen: European Environment Agency.

Few, R., Brown, K., and Tompkins, E. L. (2007). Public participation and climate change adaptation: avoiding the illusion of inclusion. Clim. Policy 7, 46-59. doi: $10.1080 / 14693062.2007 .9685637$

Flyvbjerg, B. (2006). Five misunderstandings about case-study research. Qual. Inq. 12, 219-245. doi: 10.1177/1077800405284363

Ford, J. D., Keskitalo, E. C. H., Smith, T., Pearce, T., Berrang-Ford, L., Duerden, F., et al. (2010). Case study and analogue methodologies in climate change vulnerability research. Wiley Interdiscip. Rev. Clim. Change 1, 374-392. doi: $10.1002 /$ wcc. 48

Future Earth. (2013). Future Earth Initial Design: Report of the Transition Team. Paris, International Council for Scientific Unions (ICSU).

Groot, A. K., Hollaender, K., and Swart, R. (2014). Productive Science-Practice Interactions in Climate Change Adaptation. Lessons From Practice. A CIRCLE-2 Research Policy Brief. Lisbon: Foundation of the Faculty of Sciences.

Hedger, M. M., Connell, R., and Bramwell, P. (2006). Bridging the gap: empowering decision-making for adaptation through the UK Climate Impacts Programme. Clim. Policy 6, 201-215. doi: 10.1080/14693062.2006.9685595

Hegger, D. L. T., Lamers, M., van Zeijl-Rozema, A., and Dieperink, C. (2012). Conceptualising joint knowledge production in regional climate change adaptation projects: success conditions and levers for action. Environ. Sci. Policy 18, 52-65. doi: 10.1016/j.envsci.2012.01.002

Hirsch Hadorn, G., Hoffmann-Riem, H., Biber-Klemm, S., GrossenbacherMansuy, W., Joye, D., Pohl, C., et al. (eds.). (2007). Handbook of Transdisciplinary Research. Springer Verlag. 
Hjerpe, M., Storbjörk, S., and Alberth, J. (2014). There is nothing political in it: triggers of local political leaders' engagement in climate adaptation. Local Environ. doi: 10.1080/13549839.2013.872092. [Epub ahead of print].

IPCC. (2012). "Managing the risks of extreme events and disasters to advance climate change adaptation," in A Special Report of Working Groups I and II of the Intergovernmental Panel on Climate Change, eds C. B. Field, V. Barros, T. F. Stocker, D. Qin, D. J. Dokken, K. L. Ebi, et al., (Cambridge; New York, NY: Cambridge University Press), 582.

ISSC/UNESCO. (2013). World Social Science Report 2013. Paris: OECD Publishing/Unesco Publishing.

Javeline, D. (2014). The most important topic political scientists are not studying: adapting to climate change. Perspect. Politics doi: 10.1017/S1537592714000784. [Epub ahead of print].

JPI Climate. (2010). JPI Climate Strategic Research Agenda.

Knowledge for Climate. (2012). Climate Adaptation Research in The Netherlands. Utrecht: Knowledge for Climate brochure.

Mauser, W., Klepper, G., Rice, M., Schmalzbauer, B. S., Hackmann, H., Leemans, R., et al. (2013). Transdisciplinary global change research: the co-creation of knowledge for sustainability. Curr. Opin. Environ. Sust. 5, 420-431. doi: 10.1016/j.cosust.2013.07.001

Merkx, F., Roks, D., and Wardenaar, T. (2012). Impact of Climate KnowledgeSocietal Impact Analysis of The Research Programmes Climate Changes Spatial Planning and Knowledge for Climate (in Dutch). The Hague: Rathenau Instituut.

Moser, S. C. (2010). Now more than ever: the need for more societally relevant research on vulnerability and adaptation to climate change. App. Geogr. 30, 464-474. doi: 10.1016/j.apgeog.2009.09.003

Moser, S. C., and Boykoff, M. T. (eds.). (2013). Successful Adaptation to Climate Change: Linking Science and Practice in a Rapidly Changing World. London: Routledge.

Moss, R., Wilbanks, T. J., and Wright, S. B. (2014). "The state of the art in adaptation science, policy and practice in the United States," in Climate Change Adaptation Manual: Lessons Learned from European and Other Industrialized Countries, eds A. Prutsch, T. Grothmann, S. McCallum, I. Schauser, and R. Swart (Routledge).

Moss, R. H., Meehl, G. A., Lemos, M. C., Smith, J. B., Arnold, J. R., Arnott, J. C., et al. (2013). Hell and high water: practice-relevant adaptation science. Science 342, 696-698. doi: 10.1126/science.1239569

Murtinho, F., and Hayes, T. M. (2012). Adaptation in resource-dependent communities: a call for greater methodological clarity in adaptation field research. Soc. Nat. Resour. 25, 513-522. doi: 10.1080/08941920.2011.604068

Mustelin, J., Kuruppu, N., Kramer, A. M., Daron, J., de Bruin, K., and Noriega, A. G. (2013). Climate adaptation research for the next generation. Clim. Dev. 5, 189-193. doi: 10.1080/17565529.2013.812953

NCCARF. (2012). Climate Change Adaptation Research in Australia An Overview of Research Funded by the National Climate Change Adaptation Research Facility. Brisbane, QLD: Publication 10/12. NCCARF.

Nowotny, H., Scott, P., and Gibbons, M. (2001). Re-Thinking Science: Knowledge And The Public in an Age of Uncertainty. Cambridge: PolityPress.

O'Brien, K. (2012). Global environmental change II: from adaptation to deliberate transformation. Prog. Hum. Geogr. 36, 667-676. doi: $10.1177 / 0309132511425767$

O'Brien, K., and Hochachka, G. (2010). Integral adaptation to climate change. J. Integr. Theor. Pract. 5, 89-102.

Patt, A. (2013). Should adaptation be a distinct field of science? Clim. Dev. 5, 187-188. doi: 10.1080/17565529.2013.821054

Pauli, L. (2013). "Transdisciplinarity, responsibility and Horizon 2020," in Presentation at Transdisciplinary Research for Sustainability (TDRS) Conference Held in Prague (Prague). 23-24 May 2013.
Pielke, R. A. Jr., Prins, G., Rayner, S., and Sarewitz, D. (2007). Climate change 2007: lifting the taboo on adaptation. Nature 445, 597-598. doi: 10.1038/ $445597 \mathrm{a}$

Pohl, C. (2008). From science to policy through transdisciplinary research. Environ. Sci. Policy 11, 46-53. doi: 10.1016/j.envsci.2007.06.001

Pohl, C. (2011). What is progress in transdisciplinary research? Futures 43, 618-626. doi: 10.1016/j.futures.2011.03.001

Pollitt, C., and Hupe, P. (2011). Talking about government. Public Manag. Rev. 13, 641-658. doi: 10.1080/14719037.2010.532963

Preston, B., Mustelin, J., and Maloney, M. (2013). Climate adaptation heuristics and the science/policy divide. Mitig. Adapt. Strat. Glob. Change doi: 10.1007/s11027013-9503-x. [Epub ahead of print].

Rayner, S., and Malone, E. L. (eds.). (1998). Human Choice and Climate Change. Washington, DC: Battelle Press.

Rice, M. (2013). Spanning disciplinary, sectoral and international boundaries: a sea change towards transdisciplinary global environmental change research? Curr. Opin. Environ. Sust. 5, 409-419. doi: 10.1016/j.cosust.2013. 06.007

Russell, A. W., Wickson, F., and Carew, A. L. (2008). Transdisciplinary research: context, contradictions and capacity. Futures 40, 460-472. doi: 10.1016/j.futures.2007.10.005

Swart, R., Prutsch, A., Grothmann, T., Schauser, I., and McCallum, S. (2014). "Avoid maladaptation," in Climate Change Adaptation Manual: Lessons Learned from European and Other Industrialized Countries, eds A. Prutsch, T. Grothmann, S. McCallum, I. Schauser, and R. Swart (Routledge).

Tamura, M., Yasuhara, K., Shirai, N., and Tanaka, M. (2014). "Wise adaptation to climate change: Japan," in Climate Change Adaptation Manual: Lessons Learned from European and Other Industrialized Countries, eds A. Prutsch, T. Grothmann, S. McCallum, I. Schauser, and R. Swart (Routledge).

Vink, M. J., Dewulf, A., and Termeer, C. J. A. M. (2013). The role of knowledge and power in climate change adaptation governance: a systematic literature review. Ecol. Soc. 18, C7-C46. doi: 10.5751/ES-05897-180446

Voss, J.-P., Bauknecht, D., and Kemp, R. (2006). Reflexive Governance for Sustainable Development. Edward Elgar Publishing.

WEF. (2013). Global Risks 2013. Geneva: World Economic Forum.

WEF. (2014). Global Risks 2014. Geneva: World Economic Forum.

Wickson, F., Carew, A. L., and Russell, A. W. (2006). Transdisciplinary research: characteristics, quandaries and quality. Futures 38, 1046-1059. doi: 10.1016/j.futures.2006.02.011

Conflict of Interest Statement: The authors declare that the research was conducted in the absence of any commercial or financial relationships that could be construed as a potential conflict of interest.

Received: 25 April 2014; accepted: 14 June 2014; published online: 02 July 2014.

Citation: Swart R, Biesbroek R and Capela Lourenço T (2014) Science of adaptation to climate change and science for adaptation. Front. Environ. Sci. 2:29. doi: 10.3389/ fenvs.2014.00029

This article was submitted to Interdisciplinary Climate Studies, a section of the journal Frontiers in Environmental Science.

Copyright (c) 2014 Swart, Biesbroek and Capela Lourenço. This is an open-access article distributed under the terms of the Creative Commons Attribution License (CC BY). The use, distribution or reproduction in other forums is permitted, provided the original author(s) or licensor are credited and that the original publication in this journal is cited, in accordance with accepted academic practice. No use, distribution or reproduction is permitted which does not comply with these terms. 